\title{
Documenting and Interpreting the Transition Reality through the Literary: Based on the Novel The Triumph of Gjergj Elez Alia by Ridvan Dibra ${ }^{1}$
}

\author{
Valbona Karakaçi \\ Department of Literature, University of Shkodra, Albania, \\ valbonakarakaci@yahoo.co.uk
}

\section{Doi:10.5901/mjss.2013.v4n3p503}

\begin{abstract}
Closed societies (like the communist ones) after 1989, facing the challenge of being transformed into open societies, built intermediate realities that enabled the bridging from transition into developed societies (an ongoing process). Such realities were massive migration, pyramid schemes, great demographic changes, etc. Whereas the numeric pressure of such phenomena increased, the inherited formal language had naturally failed in articulating and documenting them (how could the cheaters heading the pyramid schemes be formally called? The colloquial language had resolved this challenge by calling them for instance The Competent). At this moment, the role of literature becomes decisive for the memorization of the country's history. Literature documents transformation and by documenting it, it transforms itself. In this case, the documentation must not be understood as factual evidence, but as an experience record, which expresses deeper realities than the facts themselves (experience as a source and as a consequence of the fact). The objective of this paper will be the observation of a new trend in the Albanian literature produced during the transition aiming to describe a new literary coherence, which uses techniques of modern and postmodern writing, with a view to providing a hypothesis about how the literature developed in a way to overcome the challenge of expressing the reality.
\end{abstract}

Keywords: transition; monologue literature; minimal subject, literary coherence; modern and postmodern.

\section{Introduction}

This paper is an epistemological endeavor ${ }^{2}$, the aim of which is to cast light on the act of writing during the transition period. The transition period in Albanian literature coincides with modernist and postmodernist experiments. For this reason, the theoretical basis is grounded on these two approaches, without going deeper into their division. The definition provided by the French philosopher Jean Francois-Lyotard that "the postmodern is undoubtedly part of the modern" 3 , has been utilized as a theoretical framework, besides the focus is not on the belongingness of Dibra's work into one or another literary school.

The conclusion is not exhaustive at this stage of our study, since only one literary work is being reviewedsuggested by the author Dibra himself- as a sample of the argument of transition within the gallery of his work, and beyond (i.e. works of other authors that address transition Methodology

The research method consists in direct interviews with the author, as a complement to modern and postmodern theories and findings coming from the analysis of the literary text. The interviews served also to verify the results and built the text's perspective referring to an "open work". ${ }^{4}$

The social context of transition period based on literature review served to build the context understanding and position the literature within the social dimension and via versus.

\footnotetext{
1 The author in question has won numerous national awards in prose in Albania and Kosovo.

2 Epistemology addresses the study of knowledge and validation of our beliefs. As a study concerning knowledge, it answers such questions as sufficient knowledge conditions, their sources, structures and limits etc., whereas as a study concerning the validation (verification) of our beliefs, epistemology answers such questions as how should we understand the concept of justification/validation (verification) of our beliefs, what makes the justified/validated beliefs verifiable, the verification (validation) should take place inside or outside etc.

${ }^{3}$ Lyotard believes that postmodern is "a part of the modern," and there is a circular relation between modern \& postmodern. (p44) "A work can become modern only if it is first postmodern. Postmodernism;Kis not modernism at its end but in the nascent state, and this state is constant" (p44).

${ }^{4}$ According to Dibra, the work was designed as a triptych. The reader has received only the first two books. We are still waiting for the third book. (Source: interview with the author, April 2013).
} 


\section{Hypothesis}

In the following paragraphs I present my argument in the form of two hypotheses: whereas the first one concerns Dibra's work in relation to the literary act of writing, the latter concerns the position of the author vis-à-vis transition literature.

\subsection{Hypothesis 1 about Dibra's work and the literary act of writing:}

The work leads into self-awareness of writing through (Re)presentation and (Re)production (the former being the modern and the latter the postmodern), which both legitimize the literary act of writing and consequently its transformation from subjective into objective writing. Therefore the author is empowered, which will likely guide the evolution of the writer in general and the subject in question in particular.

The schematic presentation is given below:

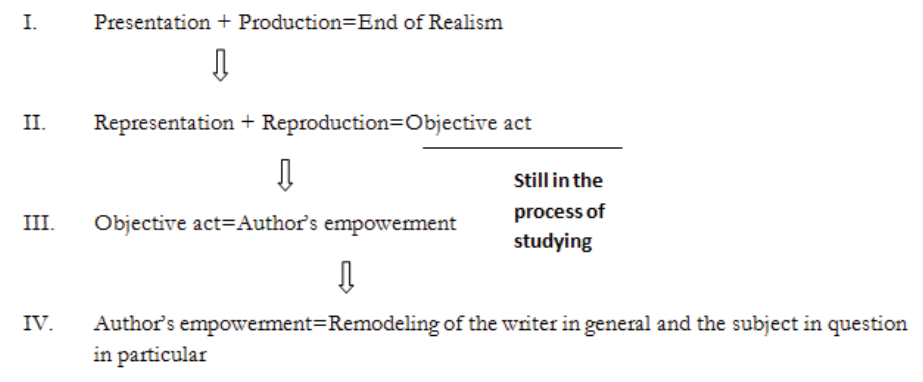

\subsection{Hypothesis 2 about the transition-writer/literature relationship}

Transition incorporates reactions that people (in this context by people we mean writers/literature) demonstrate in a period of change. The change impacts even literature, where a tendency to think over the literary act of writing is obvious, pressured by a literature, which tends to reconstruct itself.

It is likely that in several cases (Dibra's work) literature neutralizes the external reality focusing on the internal reality, which is "Timeless", thus, as a matter of fact, literature avoids the theme of transition although the literature itself is in transition.

This kind of neutralization utterly coincides with the need for a new coherence, and writing (or producing literature) does nothing else but utilizes its own potential, which, as Bill Stott suggests "is a constant transition process".

The schematic presentation is given below:

i. Reflection on the literary act of writing $\rightarrow$ a new literary coherence = Literature in a cycle of perpetium transition

ii. Literature's tendency in transition -> (i) The theme of transition is avoided (monologue literature, "timeless", and "personalized" literature)

iii. A new literary coherence used as a path to get out of the crisis, traditional literature undergoes under transitional period

Argumentative exposition of the conclusion based on The Triumph of Gjergj Elez Alia by Ridvan Dibra

\section{Presentation of the work and author 5 :}

It is about an author who was born at the end of ' 50 s of the last century, when Albanian literature was making efforts to leave behind/surmount the first stage of its post-war development and who began to write at the turn of 1980-1990, at a time when both Albanian literature and culture were bidding farewell to a heavy and long epoch, the epoch of socialist realism and were about to enter a new period, with a lot of uncertainties- the period of aesthetic pluralism...

\footnotetext{
5 The presentation of the work is intentionally taken from the press of the time http://www.gazetashqip.com/kulture /7a8fa69b85f004fcb10651c75ed07d88.html
} 
Dibra's Gjergj Elez Alia, unlike his ballad prototype, is not a warrior, or a fighter but a writer. He spends day and night at the writing-desk, near the white sheets, on which he puts down his life and deeds. His drama does not start with the heroic line: "The bravest of the bravest Gjergj Elez Alia", but with the prosaic paraphrase of this line: "A man like all men that Gjergj Elez Alia". Starting from the creation of the folk genius about Gjergj Elez Alia, coined by the scholars at certain times as a "ballad" and at others as a "legendary heroic song", the writer Ridvan Dibra wrote two novels about this topic: "The Triumph of Gjergj Elez Alia" (1999) and "The Second Triumph of Gjergj Elez Alia" (2002).

\section{Illustration of Hypotheses 1 and 2 based on Dibra's work:}

\subsection{End of realism versus avoidance of the theme of transition (minimalist plot)}

Nothing in the novel's plot incorporates elements that are reminiscent of reality. Between the outside world (reality) and the inside world (author), the writer has chosen the latter. Thus we notice the tendency toward a minimalist plot, as a reaction to the outside reality continuously changing (transition):

Gjergj is locked up in his tower-house because of objective reasons "his wounds" and rarely gets out of it "due to shame or glory/fame" (shame and glory/fame are natural features of transition) versus the writer as he is nailed down to the same writing-desk (description of the writing-desk where Gjergj puts his notes down and room details); Both Dibra as a writer and Gjergj as a warrior who writes, are locked up, finding salvation inside the room but the subjects are somewhere out. These outer subjects are brought to Gjergj by the represented characters in Dibra's work (i) his sister (ii) Nora, and (iii) his memories and sometimes even (iv) escapes (leaving the tower-house)...What is left to Dibra is reproduction of the represented history of Gjergj, as Dibra states, the work was written intensively being stuck at the writing-desk for very long hours.

1.4 (Re)presentation + (Re)production = Objective literary act of writing =Author's empowerment ${ }^{6}$ versus Building a new literary coherence (monologue, "timeless", and "personalized" literature) that in reality bears witness to the crisis the literature is going through

Representation and reproduction in this literary work are realized through a complicated process of personalization and depersonalization, acquisition-destruction and alienation, in an endeavor to build a new coherence of the literary act of writing. Although experimental, the whole of it seems to be objectively and carefully molded by the author. The work is a persistent attempt toward the reason "why do I write?" made at the right time, at the beginning of Dibra as a writer, upgraded to another level: literature under reconstruction, which needs a new coherence for the literary act of writing. As such, this work positions itself as a cornerstone at Dibra's EGOBOKA ${ }^{7 "}$ and the Albanian literature of transition.

Thus, the major character Gjergj endeavors to write like a writer. Gjergj and Dibra are both at first steps (Dibra's third novel). Gjergj is surrounded by bards and minstrels, who narrate well-known events in a very rigid manner versus Dibra, who is also surrounded by the traditional literature. They both try to escape from the conventional model.

Deconstructing of myths and legends (transformation of Gjergj's ballad) is natural because transition suffers from a lack of references and the old ones are inclined to collapse, whereas the notion of time is neutralized by letting the work to be out of time.

Time is neutralized because the cultivated writer (Gjergj) cohabitates with the bard, the character (Gjergj) lives simultaneously with the writer (Gjergj narrates himself).

In transition, people face a lot of questions that are continually transformed and the individual in transition chooses either not to think about them,or to act, or meditate on them and not act at all. It seems that Dibra (i.e. the writer in transition) has chosen to build the coherence of his work upon the latter alternative. Such a choice becomes decisive for his work, but it could be also generalized as a new form in literature. Nevertheless, the tension is unavoidable as the content is rather more a mood than an action, which leads into a special expressive form; both mood as content and the special expressive form build the new coherence. The features of this special expressive form to Dibra are characterized by poor, tense, and symmetrical dialogue; the dialoguers are allies that at any moment, risk to be transformed into adversaries. The impossibility of alliance or unstable alliances are natural features of transition.

Brother - sister (sister should get married but stays with her brother)

${ }^{6}$ Michael Foucault (1926-1984) embraces power from an unusual angle of knowledge, as a system of thought that might become controlling, i.e. socially and institutionally legitimized. Extracted from "Intellectuals and Power: A Conversation between Michel Foucault and Gilles Deleuze," (1972). Trans. in LCM.

7 In Dibra's work, Egoboka represents the space where the action takes place 
Fiancé - fiancée (Nora loves Gjergj but he has other plans already)

Winners - Losers (Gjergj's friend takes the winner's trophy from Gjergj)

\section{Author's empowerment $=$ Remodeling of the literary work and act of writing in transition}

According to the expectation of the two above mentioned hypothesis, the works' remodeling should take place in the second book/part of the triptych (which is likely to start becoming more social) and in the probable third book/part. The latter books/parts fall out of the scope of the present study.

\section{Conclusions: the writer's tendency in transition}

Tendency toward a personalized literature makes the latter go through a crisis (it transfers the transition/change from the writer to literature), but in essence empowers the writer himself (James Joyce prior to writing Ulysses wrote $A$ Portrait of the Artist as a Young Man), which in the last instance can reconstruct literature by building a new literary work coherence in a constantly changing context. Initially, the reality (context) is neutralized to enable its re-acquisition at the moment when the author has been empowered.

\section{References}

Appignanesi, R.\&Garratt,C.\&Sardar, Z.(2003). Introducing Postmodernism: A Graphic Guide by Icon Books Ltd,.Cambridge. Dibra, R. (1999). The Triumph of Gjergj Elez Alia, Onufri:Tirane.

Foucault, M. (1972) Intellectuals and Power: A Conversation between Michel Foucault and Gilles Deleuze, Trans. in LCM. Vendi, Shtepia Botuese.

Lyotard, Jean-François. (1984). The Postmodern Condition: A Report on Knowledge, Manchester University Press.

Lyotard, Jean-Francois. (1985). Note on the Meaning of 'Post-'. Docherty, Thomas, ed.Stott, Bill. (1991). Write to the Point: And Feel Better About Your Writing, 2nd ed. Columbia University Press.

O'Donnell, Guillermo, Philippe Schmitter, and Laurence Whitehead, eds. (1986). Transitions from Authoritarian Rule: Prospects for Democracy. Baltimore: Johns Hopkins University Press. 